\title{
SISTEM MONITORING REALTIME DETAK JANTUNG DAN KADAR OKSIGEN DALAM DARAH PADA MANUSIA BERBASIS IoT (INTERNET of THINGS)
}

\author{
Apriliaa $^{1)}$, Tan Suryani Sollu' ${ }^{2)}$ \\ ${ }^{1)}$ Program Studi S1 Teknik Elektro, Fakultas Teknik, Universitas Tadulako \\ ${ }^{1)}$ E-mail : apriliasolihin23@gmail.com \\ ${ }^{2}$ Dosen Teknik Elektro Universitas Tadulako \\ ${ }^{2)}$ E-mail : tansuryani@yahoo.com
}

\begin{abstract}
Heart rate and oxygen levels in the blood are very important for medical personnel to know the patient's health condition, with the existing real-time of heart rate monitoring system and oxygen levels in the blood based on IoT, it can facilitate the workload of medical personnel. This tool uses the Max30100 sensor to detect heart rate and oxygen levels in the blood and NodeMCU ESP8266 as controlling and sending sensor data to the IoT platform on android and PC wirelessly. The results of sending heart rate data and oxygen levels in the blood on Blynk and web servers have an error alignment average of $1.7 \%$ and $0 \%$. and measurements have an average of $87 \mathrm{bpm}$ and $96 \%$ of $\mathrm{SpO} 2$ in adolescents 20-24 years with the results of the measurements indicate the patient's condition is normal.
\end{abstract}

Keywords : monitoring system, Max30100, NodeMCU ESP8266, Android, PC

\section{PENDAHULUAN}

Jantung dan paru-paru merupakan bagian alat yang paling vital dalam tubuh manusia dan saling berkaitan satu sama lain, jantung ialah salah satu organ pada tubuh manusia yang berperan dalam sistem peredaran darah sesuai fungsinya yaitu mengedarkan darah ke seluruh tubuh [1]. Sedangkan paru-paru ialah salah satu organ pada sistem pernapasan (respirasi) dan berhubungan dengan sistem peredaran darah (sirkulasi) yang berfungsi untuk mengeluarkan karbondioksida (CO2) dan untuk menyediakan oksigen sebagai bahan bakar untuk metabolisme tubuh manusia. Semakin besar metabolisme pada suatu organ, maka semakin besar aliran darahnya sehingga denyut jantung akan mempercepat denyutannya [2], detak jantung dan kadar oksigen dalam darah pada manusia sangat penting untuk dimonitioring karena keduanya merupakan salah satu alat vital sign yang penting.

Sistem monitoring realtime detak jantung dan kadar oksigen dalam darah pada manusia berbasis IoT (Internet of Things) merupakan rancangan perangkat keras yang diusulkan peneliti untuk dapat menutupi kekurangan yang ada di rumah sakit ataupun tenaga medis terhadap pasien. Alat ini menggunakan sensor detak jantung dan persentasi kadar oksigen dalam darah dilengkapi dengan NodeMCU ESP8266 serta platform Blynk dan web server berfungsi sebagai media pembacaan dan penerima data sensor yang digunakan untuk mempermudah suatu proses monitoring kesehatan pasien.

Alat yang di kembangkan dalam penelitian ini mampu memonitoring secara realtime detak jantung dan kadar oksigen dalam darah pada manusia tanpa menggunakan kabel (wireless) sehingga tenaga medis dengan mudah memonitoring kesehatan pasien. Perancangan alat ini menggunakan NodeMCU ESP8266 sebagai pengendali dalam sistem pengontrolan perangkat keras maupun ke platform IoT 
Blynk dan web server, platform Blynk dan web server yang diusulkan akan terintegrasi dangan android dan personal komputer (PC). Keterlambatan pengiriman data sensor ke platform IoT disebabkan kondisi kecepatan internet yang kurang baik atau tidak setabil, keterlambatan pengiriman data sensor ke platform IoT tidak akan lebih dari 2 detik.

\subsection{Monitoring Kesehatan}

Monitoring kesehatan ialah kegiatan yang seharusnya dilakukan secara rutin oleh seseorang untuk dapat mengetahui kondisi kesehatan setiap 3 bulan sekali, monitoring kesehatan, pengontrolan kesehatan atau biasa juga disebut medical check up (pemeriksaan kesehatan secara menyeluruh) merupakan kegiatan pengecekan tandatanda vital manusia yang meliputi frekuensi denyut jantung, frekuensi pernapasan atau kadar oksigen dalam darah, suhu tubuh dan tekanan darah. Melalui pemeriksaan yang dilakukan diharapkan suatu penyakit atau gangguan kesehatan dapat dideteksi sejak dini, pengecekan ini sekaligus berguna untuk merencanakan metode penanganan dan pengobatan yang tepat sebelum penyakit berkembang [3]

\subsection{Kadar Oksigen Dalam Darah}

Tubuh manusia membutuhkan dan mengatur keseimbangan oksigen yang sangat tepat dan spesifik dalam darah. Tingkat saturasi oksigen darah arteri normal pada manusia adalah 90-100\%. Jika kadarnya di bawah 90\% dianggap rendah dan disebut hipoksemia. Kadar oksigen darah arteri di bawah $80 \%$ dapat mengganggu fungsi organ seperti otak dan jantung, dan kadar oksigen darah arteri di bawah $70 \%$ dapat menghilangkan kesadaran, dan harus segera ditangani. Kadar oksigen rendah yang terus-menerus dapat menyebabkan jantung berhenti.

\subsection{Sistem Detak Jantung}

Detak jantung berfungsi untuk memompa darah ke seluruh bagian tubuh. Jantung merupakan organ tubuh yang sangat vital dan merupakan organ yang tidak pernah berhenti bekerja. Saat tubuh tertidur jantung tetap bekerja memompa darah agar jaringan tubuh tetap mendapat pasokan oksigen dan zat-zat lain yang diperlukan. Jantung tersusun atas sel otot jantung yang terus berkontraksi dan berelaksasi tanpa merasa lelah.

Tabel 1 Klasifikasi detak jantung normal

\begin{tabular}{|c|c|c|}
\hline \multicolumn{1}{|c|}{ Umur } & $\begin{array}{c}\text { Detak } \\
\text { Jantung } \\
\text { Normal }\end{array}$ & $\begin{array}{c}\text { Maksimum } \\
\text { Detak } \\
\text { Jantung }\end{array}$ \\
\hline 3 bulan - 3 tahun & $98-168$ BPM & 215 BPM \\
\hline $3-12$ tahun & $52-136 \mathrm{BPM}$ & $210 \mathrm{BPM}$ \\
\hline 12 - 20 tahun & $47-150$ BPM & 205 BPM \\
\hline 20 - 30 tahun & $70-165$ BPM & 200 BPM \\
\hline $30-40$ tahun & $80-160$ BPM & 185 BPM \\
\hline $40-50$ tahun & $85-150$ BPM & 175 BPM \\
\hline $50-60$ tahun & $70-140$ BPM & 165 BPM \\
\hline $60-70$ tahun & $60-135$ BPM & 155 BPM \\
\hline
\end{tabular}

\subsection{ESP8266 NodeMCU}

ESP8266 merupakan modul wifi yang berfungsi sebagai perangkat tambahan mikrokontroler seperti Arduino agar dapat terhubung langsung dengan wifi dan membuat koneksi TCP/IP. Modul ini juga merupakan sebuah chip yang sudah lengkap dimana didalamnya sudah termasuk prosesor, memori dan juga akses ke GPIO. Untuk pemrogramannya sendiri bisa menggunakan ESPlorer untuk Firmware berbasis NodeMCU dan menggunakan putty sebagai terminal control untuk AT Command.

Dalam pembuatan alat tugas akhir ini jenis ESP yang digunakan adalah modul ESP8266-12e. Modul ESP8266-12e ini 
memiliki GPIO yang lebih banyak dan memori yang lebih besar dari tipe-tipe dibawahnya, berikut ini merupakan konfigurasi pin outnya:

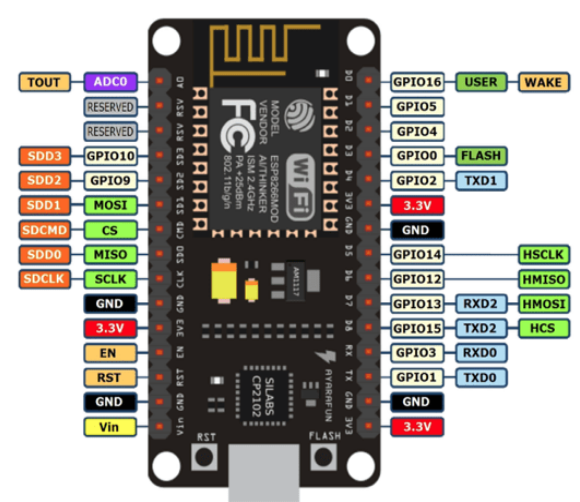

Gambar 1. NodeMCU Pin Out (Sumber : IOT BYTES, 2016)

\subsection{Sensor Max30100}

Sensor ini merupakan modul yang di dalamnya terdapat LED merah, LED inframerah, dan fotodiode. Sensor ini menggunakan komunikasi I2C. Bus driver I2C merupakan open drain, dimana saat sinyal low adalah nol volt dan sinyal high dalam keadaan floating, maka untuk dapat membaca data keluaran sensor dibutuhkan resistor pull-up pada SDA dan SCL.

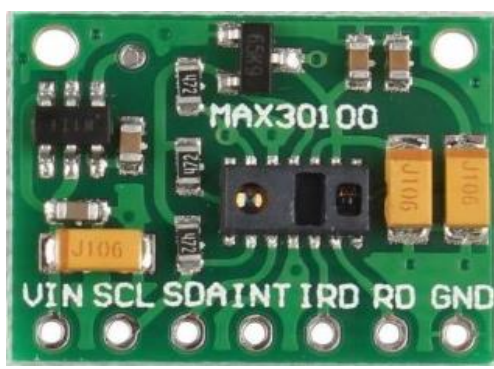

Gambar 2. Sensor Max30100

(Sumber : alselectro.com)

\subsection{IoT (Internet of Things)}

IoT adalah sebuah konsep dimana objek tertentu memiliki kemampuan untuk mentransfer data melalui jaringan wifi, jadi proses ini tidak memerlukan interaksi dari manusia ke manusia atau manusia ke komputer. Semua sudah dijalankan secara otomatis dengan program. Internet of Things biasa disebut dengan IoT, dan teknologi ini sudah berkembang pesat mulai dari teknologi nirkabel, microelectromechanical systems (MEMS) dan internet [4].

Menurut metode identifikasi RFID (Radio Frequency Identification), istilah IoT tergolong dalam metode komunikasi, meskipun IoT juga dapat mencakup teknologi sensor lainnya, teknologi nirkabel atau kode QR (Quick Response). IoT sebenarnya adalah konsep yang cukup sederhana, yang artinya menghubungkan semua objek fisik di kehidupan sehari-hari ke Internet. Istilah "Internet of Things" terdiri atas dua bagian utama yaitu Internet yang mengatur konektivitas dan Things yang berarti objek atau perangkat. Enam prinsip dasar yang menopang IoT[5].

\subsection{Arduino IDE}

Sebuah perangkat lunak yang memudahkan kita mengembangkan aplikasi mikrokontroler mulai dari menuliskan source program, kompilasi, upload hasil kompilasi, dan uji coba secara terminal serial.

Arduino IDE ini bisa dijalankan di komputer dengan berbagai macam platform karena didukung atau berbasis Java. Source program yang kita buat untuk aplikasi mikrokontroler adalah bahasa $\mathrm{C} / \mathrm{C}++$ dan dapat digabungkan dengan assembly. Penulis menggunakan arduino berbasis mikrokontroler AVR dilingkungan jenis ATMEGA yaitu ATMEGA 8, 168, 328 dan 2650. 


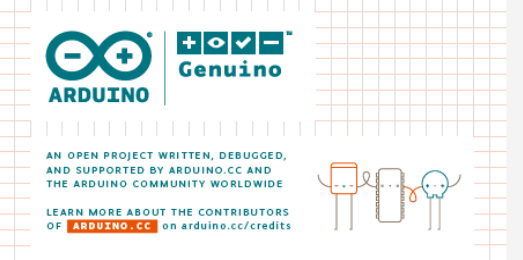

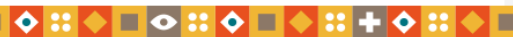

Gambar 3. Tampilan awal arduino IDE

\subsection{Blynk}

Blynk adalah aplikasi untuk iOS dan OS Android untuk mengontrol Arduino, NodeMCU, Raspberry Pi dan sejenisnya melalui Internet. Aplikasi ini dapat digunakan untuk mengendalikan perangkat hardware, menampilkan data sensor, menyimpan data,visualisasi, dan lain-lain. Aplikasi Blynk memiliki 3 komponen utama.yaitu Aplikasi, Server, dan Libraries. Blynk server berfungsi untuk menangani semua komunikasi diantara smartphone android dan hardware. Widget yang tersedia pada Blynk diantaranya adalah Button, Value Display, History Graph, Twitter, dan Email.

\subsection{Web Server}

Server web atau yang dalam bahasa inggris disebut web server adalah perangkat lunak (software) dalam server yang berfungsi untuk menerima permintaan (request) berupa halaman web melalui protokol HTTP dan atau HTTPS dari klien yang lebih dikenal dengan nama browser, kemudian mengirimkan kembali (respon) hasil permintaan tersebut ke dalam bentuk halaman-halaman web yang pada umumnya berbentuk dokumen HTML.

\subsection{Android}

Android adalah sebuah sistem operasi yang sudah menjadi salah satu kebutuhan pokok. Hampir semua orang membutuhkan alat yang satu ini untuk berkomunikasi, mencari informasi dan perkembangan berita terbaru, melakukan pekerjaan, dan berbagai aktivitas lainnya. Bahkan, saat ini hampir semua orang menggantungkan aktivitas mereka pada Android yang mereka miliki. Android adalah sebuah sistem operasi yang dirancang oleh perusahaan Google dengan basis kernel Linux dan juga berbagai perangkat lunak seperti Open Source dan lainnya.

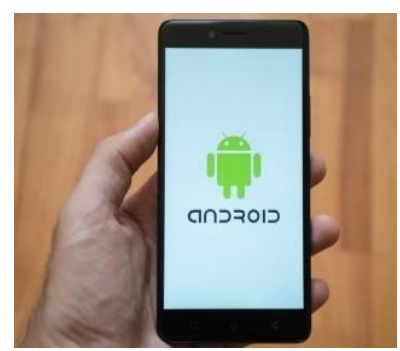

Gambar 4. Smartphone Android

(Sumber : Suara.com, 2019)

\subsection{Personal Komputer (PC)}

Personal computer adalah seperangkat komputer yang digunakan oleh satu orang pribadi saja. Fungsi utama dari PC adalah untuk mengolah data input dan menghasilkan output berupa data atau informasi sesuai dengan keinginan pengguna. Dalam pengelolaan data dari mulai memasukkan (input) data sampai akhirnya dapat menghasilkan (output) informasi,

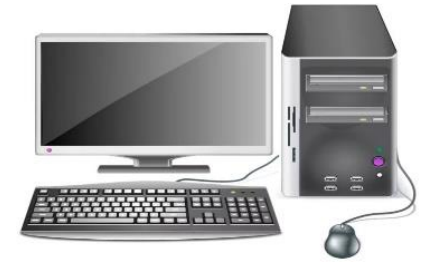

Gambar 5. Personal Computer (PC) (Sumber : imanuelapalar.wordpress.com, 2017)

\section{METODE PENELITIAN}

\subsection{Alat dan Bahan Penelitian}


Dalam penyusunan dan pembuatan skrispsi yang berjudul sistem monitoring real time detak jantung dan kadar oksigen dalam darah manusia berbasis IoT (Internet of Things), akan digunakan beberapa macam alat dan bahan sebagai berikut :

\subsubsection{Bahan Penelitian}

Bahan Penelitian terdiri dari tiga jenis, yaitu sensor Max30100, manusia dan program. Sensor Max30100 digunakan sebagai bahan untuk dapat mendeteksi detak jantung dan kadar oksigen dalam darah pasien sekaligus, manusia digunakan sebagai bahan pengambilan data detak jantung dan kadar oksigen dalam darah dan program digunakan sebagai bahan dalam mendukung software maupun hardware agar dapat menghasilkan tampilan output yang diinginkan.

\subsubsection{Alat Penelitian}

Adapun alat-alat yang digunakan pada penelitian ini antara lain ESP8266 nodeMCU sebagai pengontrollan dan pengiriman data, perangkat lunak (software) Arduino IDE sebagai media penginputan data, platform IoT sebagai media tampilan hasil data, serta PC dan android sebagai penerima dan server pendukung tampilan data

\subsection{Cara Penelitian}

Sebelum melakukan penelitian ini, sebaiknya dibuat rancangan tahap-tahap penelitian yang ingin dilakukan agar terstruktur sesuai dengan rencana, dimana penulis membuat sebuah alat yang dapat berfungsi untuk memudahkan tenaga medis dalam memonitoring detak jantung dan kadar oksigen dalam darah pasien secara jarak jauh setiap saat. Setelah itu, dipenelitian ini penulis melakukan percobaan, pengujian, dan pengamatan datadata yang diperlukan dalam penelitian ini.

\subsection{Hipotesis}

Pada penelitian dengan judul "sistem monitoing realtime detak jantung dan kadar oksigen dalam darah pada manusia berbasis IoT (internet of things)", dapat dibuat hipotesis sebagai berikut:

1. Sensor Max30100 dapat mengetahui dua kondisi pasien sekaligus yaitu detak jantung dan kadar oksigen dalam darah dengan menggunakan satu sensor saja.

2. NodeMCU ESP8266 dapat memudahkan tenaga medis dalam pengelolahan informasi detak jantung dan kadar oksigen dalam darah pasien yang dihasilkan oleh sensor Max30100 secara jarak jauh.

3. ESP8266 pada NodeMCU akan di konfigurasikan ke platfrom IoT sehingga data informasi pasien dapat di akses melalui server PC maupun android secara online (Berbasis IoT).

\section{HASIL DAN PEMBAHASAN}

\subsection{Hasil Penelitian}

Dari hasil perancangan dan penelitian yang berjudul Sistem Monitoring Realtime Detak Jantung dan Kadar Oksigen Dalam Darah Pada Manusia Berbasis IoT, maka penulis dapat menyajikan dalam bentuk alat, software, data, maupun analisa data. Berikut hasil perancangan dan penelitian yang telah dilakukan.

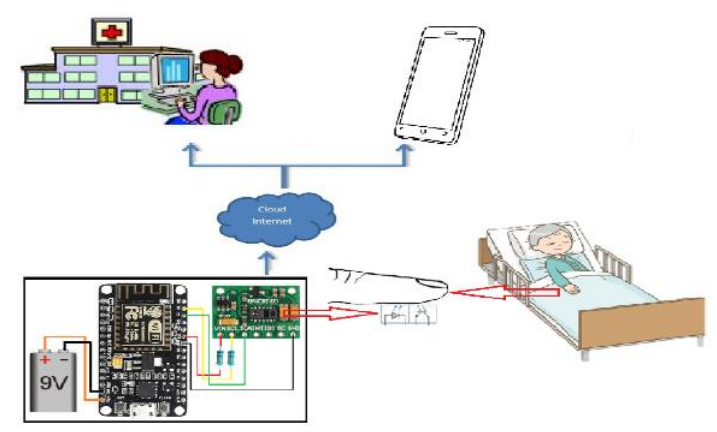

Gambar 6. Skematik rangkaian alat

\subsection{Pengujian Alat}

Pengujian alat dilakukan dengan tujuan untuk mengetahui apakah alat yang 
telah dibuat berfungsi sesuai dengan sistem yang direncanakan atau belum. Pada penelitian ini dilakukan percobaan sebanyak 10 kali pada sensor dengan 10 orang sebagai sample data dan rentang waktu yang berbeda-beda. Hal ini dilakukan untuk melihat tingkat keberhasilan sensor untuk mendeteksi serta pengiriman data ke platform Blynk pada android dan ke web server pada PC server secara wireless (berbasis IoT) maupun tingkat keberhasilan sistem secara keseluruhan.

Tabel 2. Hasil pengujian alat

\begin{tabular}{|c|c|c|c|c|c|}
\hline \multirow[b]{2}{*}{$\mathrm{No}$} & \multirow[b]{2}{*}{ Nama } & \multirow[b]{2}{*}{$\begin{array}{l}\text { Umur } \\
\text { (Tahun) }\end{array}$} & \multicolumn{2}{|c|}{ Data Pasien } & \multirow[b]{2}{*}{$\begin{array}{c}\text { Keteran } \\
\text { gan }\end{array}$} \\
\hline & & & \begin{tabular}{|l|} 
Detak \\
Jantung
\end{tabular} & \begin{tabular}{|c} 
Saturasi \\
Oksigen \\
$\left(\mathrm{SpO}_{2}\right)$
\end{tabular} & \\
\hline 1 & Muh. Philano & 9 & $\begin{array}{c}86 \\
\text { BPM }\end{array}$ & $96 \%$ & Normal \\
\hline 2 & Muh. Backhri & 14 & $\begin{array}{c}70 \\
\text { BPM }\end{array}$ & $95 \%$ & Normal \\
\hline 3 & Anang Tegar R. & 21 & $\begin{array}{c}86 \\
\text { BPM }\end{array}$ & $96 \%$ & Normal \\
\hline 4 & Theresa B. & 21 & $\begin{array}{c}80 \\
\text { BPM }\end{array}$ & $95 \%$ & Normal \\
\hline 5 & Kiki Andes H. & 21 & $\begin{array}{c}87 \\
\text { BPM }\end{array}$ & $97 \%$ & Normal \\
\hline 6 & Ryadh Dirga P. & 22 & $\begin{array}{c}96 \\
\text { BPM }\end{array}$ & $97 \%$ & Normal \\
\hline 7 & Hengki & 23 & $\begin{array}{c}84 \\
\text { BPM } \\
\end{array}$ & $95 \%$ & Normal \\
\hline 8 & Achmad Saleh & 24 & $\begin{array}{c}92 \\
\text { BPM }\end{array}$ & $96 \%$ & Normal \\
\hline 9 & $\begin{array}{c}\text { Rizana Fauzi } \\
\text { ST, MT }\end{array}$ & 35 & $\begin{array}{c}105 \\
\text { BPM }\end{array}$ & $98 \%$ & Normal \\
\hline 10 & $\begin{array}{l}\text { Ahmad Antares } \\
\text { A.ST,M,Eng.Sc }\end{array}$ & 52 & $\begin{array}{c}74 \\
\text { BPM } \\
\end{array}$ & $95 \%$ & Normal \\
\hline
\end{tabular}

Berikut perbandingan nilai data detak jantung dan kadar oksigen dalam darah pada platform Blynk pada android dan web server pada PC dengan melakukan percobaan sebanyak 10 kali dengan rentang waktu yang berbeda, hal ini dilakukan untuk melihat error pengiriman data ke platform IoT

Tabel 1. Tampilan Platform IoT

\begin{tabular}{|c|c|c|c|c|c|c|c|}
\hline \multirow{2}{*}{ No } & \multirow{2}{*}{ Waktu } & \multicolumn{2}{|c|}{ Blynk } & \multicolumn{2}{|c|}{ Web server } & \multicolumn{2}{|c|}{$\begin{array}{c}\text { Persen } \\
\text { Error }(\%)\end{array}$} \\
\hline & & $\begin{array}{c}\text { Detak } \\
\text { Jantung }\end{array}$ & $\begin{array}{l}\text { Saturasi } \\
\text { Oksigen } \\
\text { (SpO2) }\end{array}$ & $\begin{array}{l}\text { Detak } \\
\text { antung }\end{array}$ & \begin{tabular}{|l|} 
Saturasi \\
Oksigen \\
$(\mathrm{SpO} 2)$
\end{tabular} & $\begin{array}{c}\text { Detak } \\
\text { Jantung }\end{array}$ & $\begin{array}{c}\text { Saturasi } \\
\text { Oksigen } \\
\text { SpO2 }\end{array}$ \\
\hline 1 & 09:29:02 & $\begin{array}{c}78 \\
\mathrm{BPM}\end{array}$ & $97 \%$ & \begin{tabular}{|c|}
76 \\
BPM
\end{tabular} & $97 \%$ & 2 & 0 \\
\hline 2 & 09:29:08 & $\begin{array}{c}82 \\
\text { BPM }\end{array}$ & $97 \%$ & \begin{tabular}{|c|}
80 \\
BPM
\end{tabular} & $97 \%$ & 2 & 0 \\
\hline 3 & 09:29:17 & $\begin{array}{c}80 \\
\text { BPM }\end{array}$ & $97 \%$ & \begin{tabular}{|c|}
80 \\
BPM
\end{tabular} & $97 \%$ & 0 & 0 \\
\hline 4 & 09:29:27 & $\begin{array}{l}89.5 \\
\text { BPM }\end{array}$ & $97 \%$ & \begin{tabular}{|c|}
88 \\
BPM \\
\end{tabular} & $97 \%$ & 1.5 & 0 \\
\hline 5 & p9:29:4s & $\begin{array}{l}78.5 \\
\text { BPM }\end{array}$ & $96 \%$ & $\begin{array}{c}81 \\
\text { BPM }\end{array}$ & $96 \%$ & 2.5 & 0 \\
\hline 6 & $p 9: 29: 5$ & $\begin{array}{c}89 \\
\text { BPM }\end{array}$ & $97 \%$ & $\begin{array}{c}84 \\
\text { BPM }\end{array}$ & $97 \%$ & 5 & 0 \\
\hline 7 & $p 9: 30: 02$ & $\begin{array}{l}88.5 \\
\text { BPM }\end{array}$ & $97 \%$ & $\begin{array}{c}90 \\
\text { BPM }\end{array}$ & $97 \%$ & 1.5 & 0 \\
\hline 8 & 99:30:10 & $\begin{array}{c}90 \\
\text { BPM }\end{array}$ & $97 \%$ & $\begin{array}{c}90 \\
\text { BPM }\end{array}$ & $97 \%$ & 0 & 0 \\
\hline 9 & p9:30:15 & $\begin{array}{c}90 \\
\text { BPM }\end{array}$ & $97 \%$ & $\begin{array}{c}88 \\
\text { BPM } \\
\end{array}$ & $97 \%$ & 2 & 0 \\
\hline 10 & $p 9: 30: 18$ & $\begin{array}{l}88.5 \\
\text { BPM }\end{array}$ & $97 \%$ & \begin{tabular}{|c|}
88 \\
BPM \\
\end{tabular} & $97 \%$ & 0.5 & 0 \\
\hline \multicolumn{6}{|c|}{ Rata-rata error ( $\%$} & 1,7 & 0 \\
\hline
\end{tabular}

\subsection{Pembahasan}

Monitoring detak jantung dan kadar oksigen dalam darah berbasis IoT merupakan sebuah inovasi pengembangan teknologi dalam bidang kesehatan, khususnya dalam memonitoring vital sign manusia detak jantung dan kadar oksigen dalam darah, dimana data pasien akan dideteksi oleh satu sensor yaitu Max30100 dan akan di teruskan melalui serial komunikasi I2C (SDA SCL) ke Mikrokontroller yang ada pada NodeMCU untuk pengontrolan hasil keluaran sensor yang akan dikirim melalui modul ESP8266 ke cloud internet secara realtime agar dapat 
terakses oleh platform IoT Blynk pada android dan web server pada PC rumah sakit.

Cara kerja sensor Max30100 ialah dengan cara meletakan jari di atas sensor lalu sensor akan memanfaatkan sifat alami darah yaitu Hemogrobin $(\mathrm{Hb})$ yang dapat menyerap banyak cahaya untuk data $\mathrm{SpO} 2$ serta denyut alami aliran darah di dalam arteri untuk data detak jantung. Hemoglobin yang lebih banyak mengandung oksigen akan memantulkan cahaya led merah dan lebih banyak menyerap cahaya inframerah sebaliknya hemoglobin yang lebih sedikit mengandung oksigen akan menyerap lebih banyak cahaya led merah dan memantulkan cahaya inframerah selanjutnya cahaya yang terpantulkan akan di terima oleh potodetektor untuk di bandingkan serta menghitung perbedaan hemoglobin dalam darah lalu informasi akan di ubah ke nilai digital oleh mikroprosesor untuk di tampilkan.

Alat ini juga di lengkapi dengan catu daya bawaan berupa baterai agar dapat berfungsi pada kondisi tertentu seperti lampu padam atau tidak ada sumber daya lainnya dan dilengkapi dengan soket USB NodeMCU yang berfungsi untuk memasukan program pada modul ESP8266 agar dapat terhubung ke jaringan internet terdekat dan memastikan modul tetap dalam kondisi online serta dapat menjadi alternatif tambahan untuk menyalakan alat menggunakan catu daya luar seperti power bank.

Kecepatan pengiriman data pasien ke platform Blynk pada android dan web server pada PC server tergantung pada kecepatan internet server yang digunakan. Platform Blynk pada android juga di lengkapi dengan tampilan berupa grafik,nilai, tampilan gauge, dan data yang di tampilkan oleh platform Blynk akan terekam serta data dapat di kirim pada email yang terdaftar pada platform Blynk, web server pada PC server juga dilengkapi dengan tampilan berupa gambar dan plot nilai data detak jantung (BPM) dan kadar oksigen dalam darah $\left(\mathrm{SpO}_{2}\right)$. Kedua tampilan data tersebut bertujuan untuk dapat memudahkan tenaga medis untuk mengetahui kondisi pasien secara real time setiap saat dan dimanapun. Pengaksesan data pasien hanya dapat di akses oleh pihak rumah sakit yang mengetahui alamat IP data pasien pada web server, sedangkan data pasien pada platform Blynk hanya dapat di akses oleh 1 user yang telah terprogram pada NodeMCU. Tingkat error pengiriman data pasien pada platform IoT Blynk maupun web sebver sebesar $1,7 \%$ pada data BPM dan $0 \%$ pada $\mathrm{SpO} 2$, hal ini dikarenakan koneksi internet yang digunakan kurang stabil dan pengiriman data terlebih dahulu ke platform blynk pada android lalu akan diteruskan ke web server pada PC sesuai dengan program yang telah di tanamkan pada NodeMCU ESP8266

\subsubsection{Grafik Hasil Pengukuran Patien Healt Monitoirng}

Data hasil grafik pengukuran pasien sesuai dengan nomor urut tabel hasil pengujian alat yang telah lakukan.

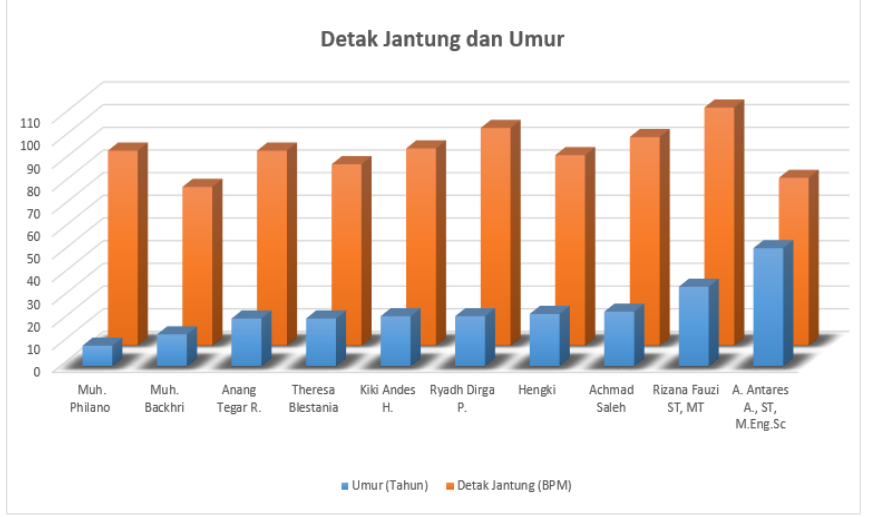

Gambar 6. Grafik Data Detak Jantung dan Umur 


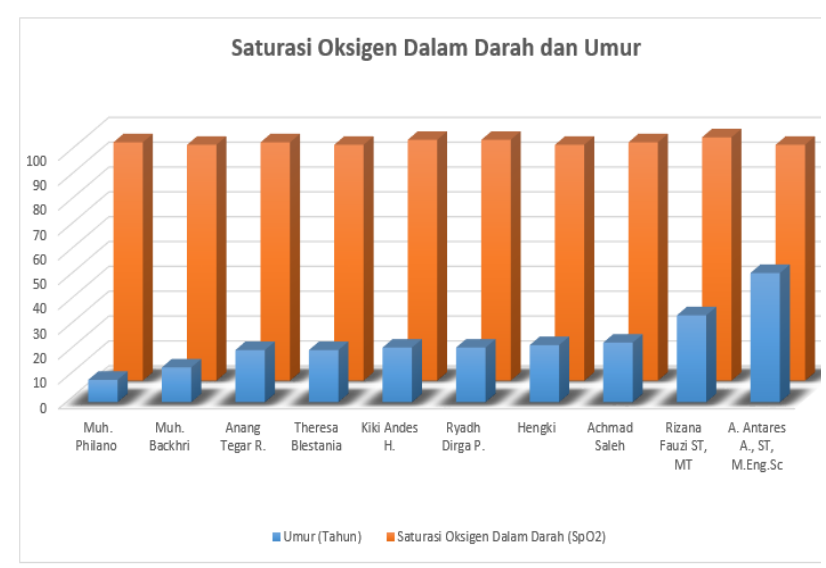

Gambar 7. Grafik Data Saturasi Oksigen

Dalam Darah dan Umur

Dari data pada gambar grafik 6 dan 7 di atas terlihat bahwa detak jantung (BPM) dan kadar oksigen dalam darah $\left(\mathrm{SpO}_{2}\right)$ yang paling tinggi dimiliki oleh Pak Fauzi dengan usia 35 tahun sedangkan detak jantung dan kadar oksigen dalam darah yang paling rendah dimiliki oleh Pak Antaris dengan usia 52 tahun, dengan rentang usia 20-24 tahun cenderung memiliki detak jantung dan saturasi oksigen yang stabil, tidak tinggi dan tidak rendah. Pengambilan data dilakukan dengan kisaran waktu 30-60 detik pada sensor dan akan mengambil nilai rata" yang di tampilkan dikarenakan setiap 1 detik data sensor akan berubah atau memperbaharui (update) sesuai dengan data yang terbaca oleh sensor $\operatorname{Max} 30100$.

\section{KESIMPULAN}

Dari data hasil perancangan dan penelitian yang telah dilakukan pada tugas akhir yang berjudul sistem monitoring realtime detak jantung dan kadar oksigen dalam darah pada manusia berbasis IoT (internet of things) maka diperoleh kesimpulan sebagai berikut :

1. Dengan adanya alat sistem monitoring realtime detak jantung dan kadar oksigen dalam darah pada manusia berbasis IoT ini dapat memudahkan tenaga medis untuk memantau kondisi vital sign pasien khususnya detak jantung dan kadar oksigen dalam darah setiap saat serta dimanapun melalui android ataupun personal komputer tanpa harus mengunjungi pasien.

2. Keterlambatan pengiriman data pada android dan personal komputer terjadi karena kondisi kecepatan internet yang kurang baik atau tidak stabil. pengiriman data terlebih dahulu ke platform blynk pada android lalu akan diteruskan ke web server pada PC sesuai dengan program delay pada software arduino IDE. Keterlambatan pembacaan sensor pada android dan PC tidak akan lebih dari 2 detik

3. Tampilan data pada android berbentuk nilai, tampilan gauge, dan grafik sehingga dapat menunjukan hasil pengukuran yang sedang berlangsung maupun hasil pengukuran yang sebelumnya, dan tampilan pada PC hanya menampilkan nilai data sensor.

4. Dengan adanya IoT (Internet of Things) maka data hasil keluaran sensor dapat ditransfer melalui jaringan tanpa memerlukan adanya interaksi dari manusia ke manusia atau dari manusia ke perangkat komputer.

\section{DAFTAR PUSTAKA}

[1] Sollu,T.S., Dewi, S., \& Amir, A. 2019. Sistem Monitoring Detak Jantung dan Suhu Tubuh Pasien Lansia Nernasis Artificial Neural Network, Jurusan Teknik Elektro, Fakultas Teknik, Universitas Tadulako.

[2] Rizqi, A. D. 2017 Akuisi Data Detak Jantung dan Frekuensi Pernapasan Berbasis Labview, Universitas Gadjah Mada. 
[3] Willy, T. 2018. Medikal Check Up, https://www.alodokter.com/medicalchec k-up-ini-yang-harus-anda-ketahui, diakses : 15 Februari 2020.

[4] Harsono Egi. 2019. Pengertian Cara Kerja dan Penerapan Pada Internet of Things,https://www.kompasiana.com/ mudamudi/5d6654b20d823006540bdb a3/pengertian-cara-kerja-danpenerapan-pada -internet-of-things, diakses : 28 Agustus 2019.

[5] Baharsyah N. Afrizal. 2019. Pengertian Internet of Things (IoT), https://www.jago anhosting.com/blog/pengertian internet-of-things-iot/, diakses :26 Agustus 2019. 